\title{
Experimental animal models for studies on the mechanisms of blast-induced neurotrauma
}

\section{Mårten Risling ${ }^{1 *}$ and Johan Davidsson ${ }^{2}$}

${ }^{1}$ Department of Neuroscience, Karolinska institutet, Stockholm, Sweden

2 Injury Prevention Group, Division of Vehicle Safety, Applied Mechanics, Chalmers University of Technology, Göteborg, Sweden

\section{Edited by:}

Ibolja Cernak, Johns Hopkins

University, USA

Reviewed by:

Joseph Long, Walter Reed Army Institute of Research, USA

Michele Laura Schaefer, Johns

Hopkins University, USA

Brock Wester, Johns Hopkins

University, USA

${ }^{*}$ Correspondence:

Mårten Risling, Department of

Neuroscience, Karolinska Institutet

Retzius väg 8, 17177 Stockholm,

Sweden.

e-mail: marten.risling@ki.se
A blast injury is a complex type of physical trauma resulting from the detonation of explosive compounds and has become an important issue due to the use of improvised explosive devices (IED) in current military conflicts. Blast-induced neurotrauma (BINT) is a major concern in contemporary military medicine and includes a variety of injuries that range from mild to lethal. Extreme forces and their complex propagation characterize BINT. Modern body protection and the development of armored military vehicles can be assumed to have changed the outcome of BINT. Primary blast injuries are caused by overpressure waves whereas secondary, tertiary, and quaternary blast injuries can have more varied origins such as the impact of fragments, abnormal movements, or heat. The characteristics of the blast wave can be assumed to be significantly different in open field detonations compared to explosions in a confined space, such an armored vehicle. Important parameters include peak pressure, duration, and shape of the pulse. Reflections from walls and armor can make the prediction of effects in individual cases very complex. Epidemiological data do not contain information of the comparative importance of the different blast mechanisms. It is therefore important to generate data in carefully designed animal models. Such models can be selective reproductions of a primary blast, penetrating injuries from fragments, acceleration movements, or combinations of such mechanisms. It is of crucial importance that the physical parameters of the employed models are well characterized so that the experiments can be reproduced in different laboratory settings. Ideally, pressure recordings should be calibrated by using the same equipment in several laboratories. With carefully designed models and thoroughly evaluated animal data it should be possible to achieve a translation of data between animal and clinical data. Imaging and computer simulation represent a possible link between experiments and studies of human cases. However, in order for mathematical simulations to be completely useful, the predictions will most likely have to be validated by detailed data from animal experiments. Some aspects of BINT can conceivably be studied in vitro. However, factors such as systemic response, brain edema, inflammation, vasospasm, or changes in synaptic transmission and behavior must be evaluated in experimental animals. Against this background, it is necessary that such animal experiments are carefully developed imitations of actual components in the blast injury. This paper describes and discusses examples of different designs of experimental models relevant to BINT.

Keywords: traumatic brain injury, TBI, blast, model

\section{INTRODUCTION}

Traumatic brain injury (TBI) is a very complex entity, often complicated by secondary injury cascades (Cernak and NobleHaeusslein, 2010). The use of improvised explosive devices (IED) in the contemporary asymmetric military conflicts and terrorist attacks has resulted in large numbers of casualties (Jaffee et al., 2009). The effects of blast waves from detonations represent an intriguing and complex scientific problem domain. Blast-induced neurotrauma (BINT) has often been referred to as the signature injury in the conflicts in Iraq and Afghanistan (Moore and Jaffee, 2010; Snell and Halter, 2010). Mild TBI is a dominating group of TBI both in civilian trauma studies and in the military setting
(Hoge et al., 2009; Snell and Halter, 2010; Ling and Ecklund, 2011). Concussion during sports activities, the prototype mild TBI in the civilian context, is often an acceleration injury. Most cases of mild TBI probably result in very limited physical lesions, although there are reports of white matter injuries (Sharp and Ham, 2011). However, many mild TBI have functional effects that last for a considerable amount of time and the underlying factors remain to be established (Terrio et al., 2009; Belanger et al., 2011; Sayer, 2012). The physics of the blast injury differ from that of trauma in the usual civilian accidents. Whether the underlying mechanism in mild TBI is the blast wave or acceleration forces must yet be determined. 
One way to understand the effects of a blast wave is to divide the mechanism into (see also Figure 1):

- Effects of the primary blast wave, thus the propagation of a supersonic pressure transient with short duration. The threshold for injuries is determined by factors such as peak pressure, duration, and shape of the wave (reflections, underpressure, etc.).

- Secondary effects of blast, i.e., due to the impact of flying objects, such as shrapnel fragments, which can generate penetrating injuries. The proportion of such injuries was larger in previous conflicts, but seems to have been reduced by improvements in helmet construction.

- Tertiary effects of blast, i.e., the result of acceleration movements, which may result in tissue shearing and diffuse injuries, such as diffuse axonal injuries (DAI).

- Quaternary effects of blast, the result of heat, smoke, or emission of electromagnetic pulses (EMP).

Many clinical TBI cases have a complex mixture of diffuse and focal injuries, which are complicated by secondary injury events. Individuals exposed to a blast often suffer from multiple injuries, i.e., pulmonary lesions or amputations. Severe blast related TBI with brain edema and vascular spasm (Armonda et al., 2006) can be assumed to be the result of a combination of more than one injury mechanisms. The propagation of blast waves through vessels into the brain and the possible effects on vascular perfusion and the function of the blood-brain barrier has been suggested to be an important mechanism for blast (Chen and Huang, 2011). It is generally very difficult to reconstruct the physics after a detonation and estimate acceleration forces. Exposure data are usually lacking in clinical BINT cases. This situation may change with acceleration probes in helmets and other efforts to create blast dosimeters (Rigby et al., 2011). Thus, the complexity of the blast physics and the TBI create a demand for systemic studies in order to obtain better knowledge regarding injury mechanisms as well as better strategies for prevention and treatment of BINT.

Thus, the clinical situation is very complex and animal trauma models can be used to study single factors involved in the pathobiology of head injury (Cernak, 2005). Experimental studies in animals therefore represent an unavoidable tool in BINT research. A considerable number of animal models have been proposed to be suitable for blast research. Examples of such models will be described and discussed in this paper. Furthermore, the importance of validating these models will be explained and a review of how experimental and clinical data can be translated will be performed.

\section{EXAMPLES OF MODELS FOR BLAST OPEN FIELD EXPOSURE}

The classical large-scale experiments in desert areas and ponds in the US employed large sets of animals of different species and sizes that were subjected to open field exposure to blast. These experiments determined thresholds for mortality and injuries such as bleeding in air filled organs such as the lungs and intestines. The potential effects on the central nervous system were however not assessed. These experiments provided fundamental data for effects of blast with simple wave forms, i.e., the Friedländer type of wave a) primary blast wave

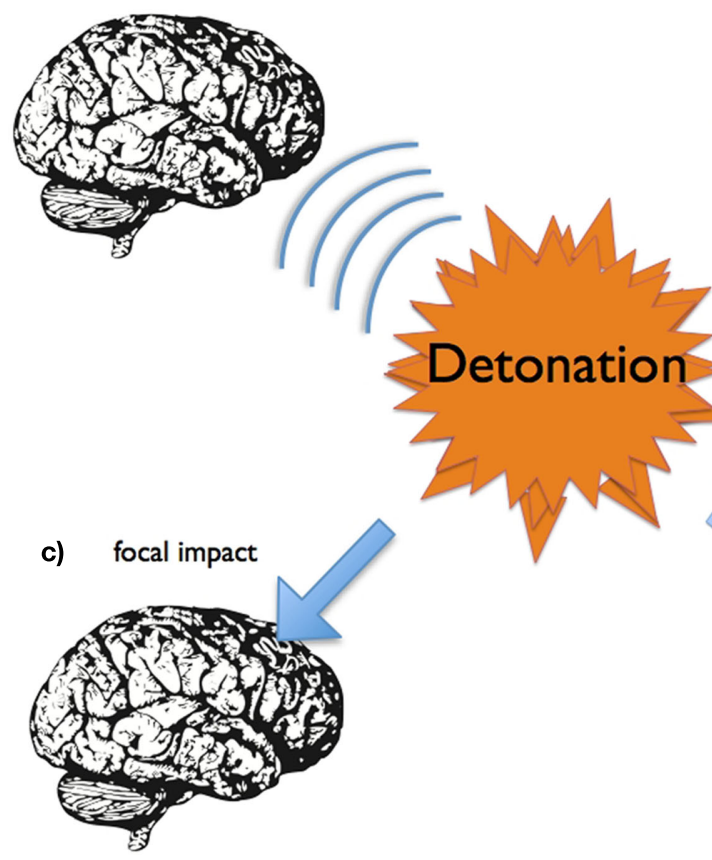

b) rotational acceleration

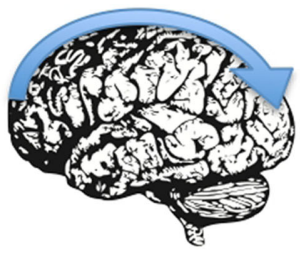

d) EMP \& heat

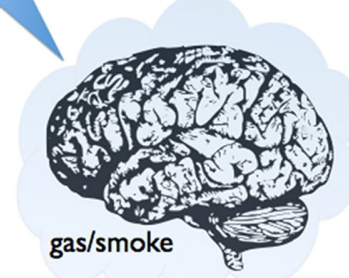

FIGURE 1 |A schematic representation of some of different mechanisms for blast-induced neurotrauma. 
and dose response curves (the Bowen curves) were determined (White et al., 1965; Richmond et al., 1967a,b; Axelsson and Yelverton, 1996; Cernak et al., 2011). These types of experiments require large amounts of explosives and dosimetry can be difficult. Outdoor conditions in combination with a large number of animals in a single experiment usually leads to a decreased control of the physiology of the experimental animals and may prevent proper tissue collection. However, open field experiments may allow for more realistic experiments with large animals that are more similar in size to humans. It also makes it possible to use waveforms relevant for simulation of IED, for example reflection from the ground or vehicles. New models employing modified open field exposures aimed to produce mild TBI include a Combat Zone-like blast scenery for mice (Rubovitch et al., 2011) and a primate model (Lu et al., 2011).

\section{BLAST TUBES FOR EXPLOSIVES}

During the 1950s large size blast tubes were created to study the effects of wave forms relevant to nuclear detonations, i.e., with a comparatively long duration of the primary peak. The tubes were often used to study how construction details such as doors could withstand a blast wave and were not primarily intended for studies in experimental animals. One exception was the studies by Clemedson at the Swedish FOA (Swedish Defence Research Establishment) using a smaller blast tube (Clemedson and Criborn, 1955) in which a charge of plastic explosives (pentaerythritol tetranitrate, PETN) was used. The system was composed of a cylindrical $400 \mathrm{~mm}$ wide cast iron tube, with a cone shaped tip where the charge was placed (Figure 2). Clemedson and his coworkers published a number of studies on vascular and respiratory effects of blasts (Clemedson et al., 1953; Clemedson and Hultman, 1954). After some time, this work was extended to include the central nervous system (Clemedson, 1956) and the cerebral vasculature (Clemedson et al., 1957). The blast tube was modified for work with rodents in the 1990s. In the current setting, the anesthetized rat is mounted in the blast tube at a distance of $1 \mathrm{~m}$ from the charge. Five grams PETN results in a peak pressure exceeding 10 bar during detonation. The animals are mounted in metallic nets or fixed to a body protection in order to limit acceleration movements and there are no fragments. Therefore, secondary and

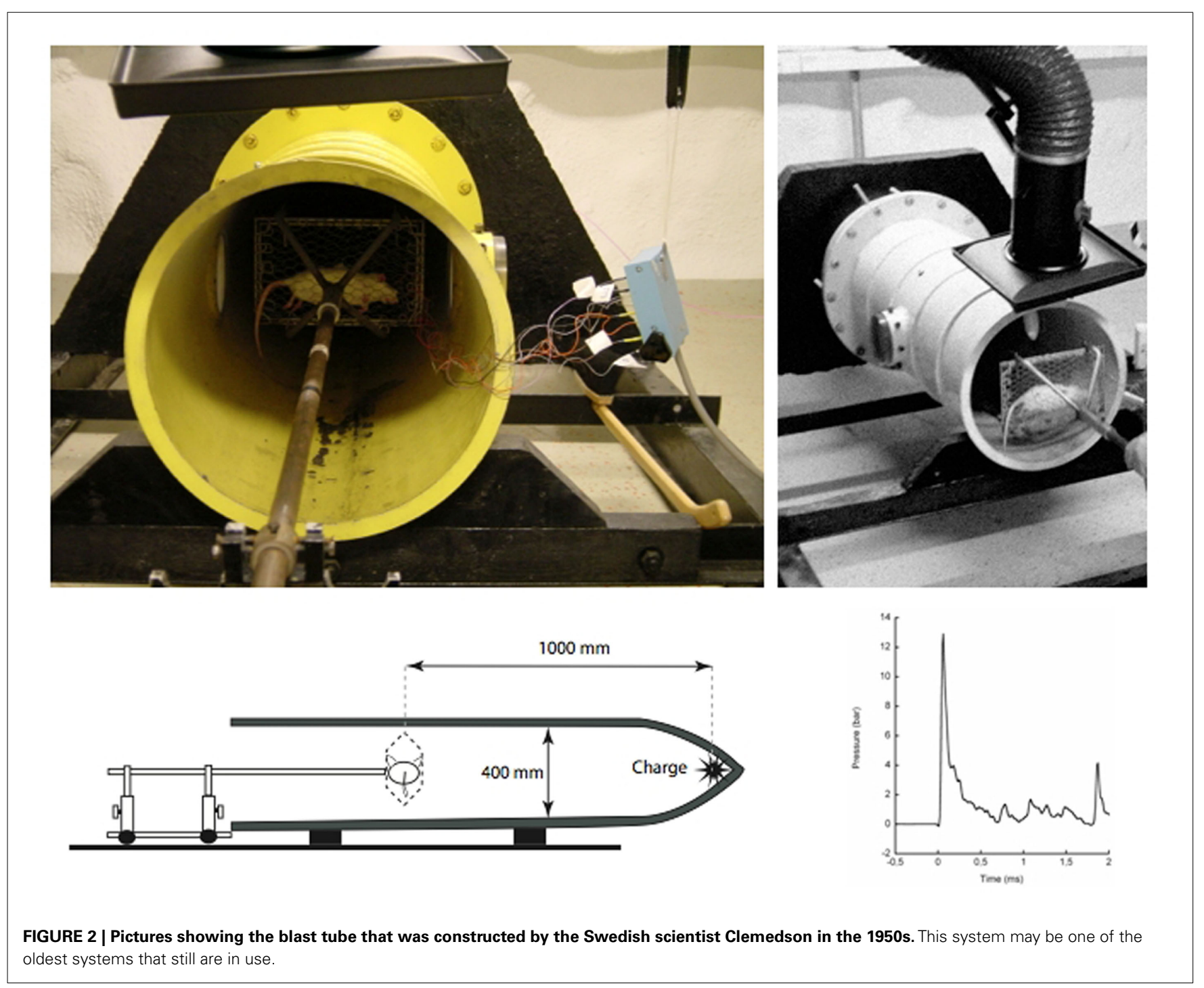


tertiary blast effects should be very limited in this model. However, smoke and gas emission contribute with quaternary blast effects. This is equipment that is used in laboratory environments with the benefit of both a fairly high level of control of the physics in the blast wave and the animal physiology. One limitation is the short duration and very simple form of the blast wave. One way to modify the blast wave would be to extend the length of the tube and/or add reflective obstacles in the tube. One other modification would be to allow for predetermined acceleration movement. Recently the Walter Reed Army Institute of Research has published interesting studies on mild BINT in swine exposed in a large size blast tube (Bauman et al., 2009; de Lanerolle et al., 2011).

\section{SHOCK TUBES WITH COMPRESSED AIR OR GAS}

Systems with compressed air were used already in the 1950s (Celander et al., 1955). Most systems comprise two chambers, separated by a membrane (Figure 3). Compressed gas is loaded into one of these chambers, referred to as the overpressure chamber or the driver section, which is separated from the other chamber, referred to as the main section or the driven section, by a diaphragm. The object, i.e., the experimental animal, is positioned somewhere in the main section. The operator can rupture the diaphragm and the compressed gas enters the main section and simulates a propagating blast wave. The main section is usually several meters long. If several overpressure chambers are positioned in a series, rather complex waveforms can be created. The duration of the pulse is usually longer and the peak pressure is much lower than in the Clemedson tube. One advantage associated with this type of shock tube is the absence of quaternary blast effects as well as other disadvantages of explosives. However, this advantage can also be regarded as a disadvantage. There are a number of modifications of the shock tube design and there seems to be a need to calibrate the different systems. Well-documented modern shock tubes can for instance be found at the Walter Reed institute (Long et al., 2009) and the US Naval Medical Research Center (Chavko et al., 2007, 2011). One very sophisticated shock tube system has been installed at the Applied Physics Laboratory at Johns Hopkins University (Cernak et al., 2011). This is a modular, multichamber shock tube capable of reproducing complex shock wave signatures. The instrumentation allows direct measurement and

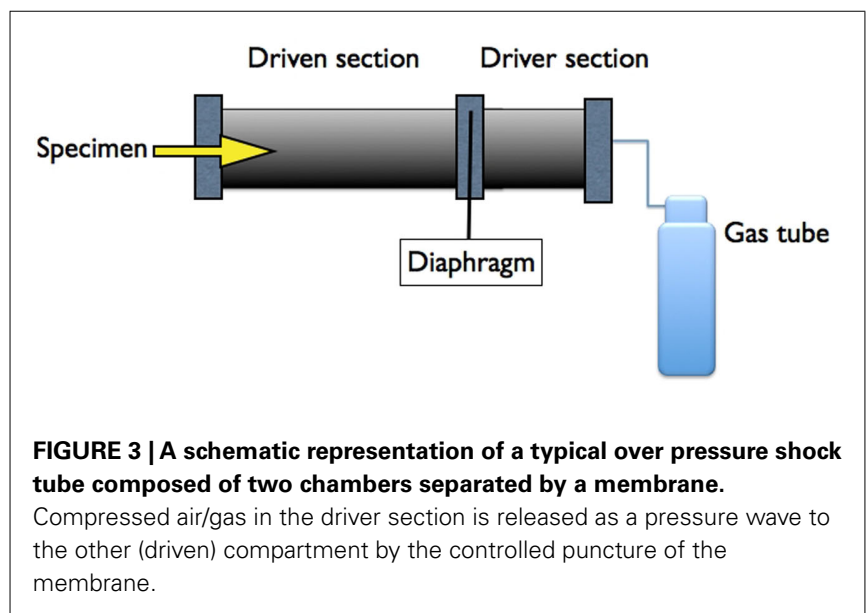

calculation of the various shock loading characteristics, including static pressure, total pressure, and overpressure impulse.

\section{MODEL FOR FRAGMENT PENETRATION}

This model can be used to mimic the more severe blast TBI, where shrapnel fragments penetrate the skull and brain tissue (Risling et al., 2004). The velocity of such fragments is assumed to be less than $300 \mathrm{~m} / \mathrm{s}$, depending on the presence and effectiveness of helmets. The anesthetized rats are placed in a stereotactic frame and a craniotomy is performed (Figure 4). A lead bullet is accelerated by air pressure in a specially designed rifle and impacts a secondary projectile (Plantman et al., 2011). The pin of the secondary projectile, guided by a narrow tube, penetrates the surface of the brain with a speed of $100 \mathrm{~m} / \mathrm{s}$. The base of the projectile is surrounded by a compressible ring that provides control of the penetration depth into the brain, which usually is set to $5 \mathrm{~mm}$. The speed and shape of the penetrating secondary projectile can be changed to obtain a variation of physical properties. The model has recently been modified for work in mice, in collaboration with Dr. Ibolja Cernak at the Applied Biophysics Laboratory at Johns Hopkins University. This penetrating TBI results in a central cavity corresponding to the actual penetration. A zone of reactive tissue, which contains a mixture of dying cells, reactive cells, and invading inflammatory cells, surrounds this cavity. Electron microscopy has demonstrated mainly extracellular perivascular edema (Risling et al., 2011).

\section{PENETRATING BALLISTIC BRAIN INJURY MODEL}

The device is designed to model both the permanent injury tract created by the path of the bullet itself and the large temporary cavity generated by energy dissipation from a penetrating object. A designed probe is inserted in the brain at the desired location and rapid inflation of an attached balloon is used to mimic the temporary cavity. The model has been characterized in a large number of studies and can presumably generate important knowledge about cavity formation during fragment penetration, although the model was specifically constructed to simulate effects of NATO $7.62 \mathrm{~mm}$ rounds (Williams et al., 2005, 2007).

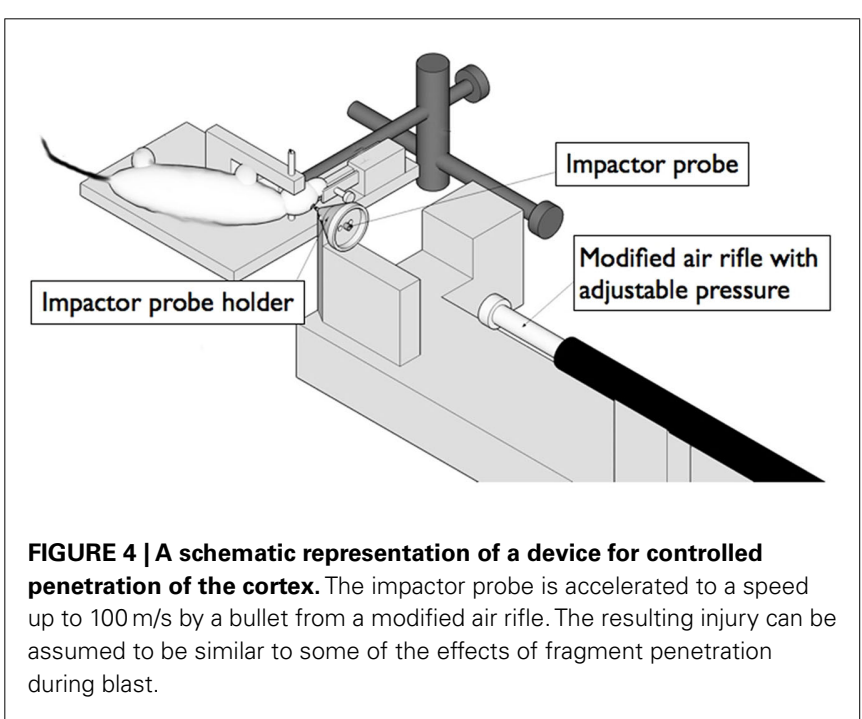




\section{MODELS FOR ACCELERATION/DECELERATION TBI}

The rotational weight drop model that was developed by Marmarou and coworkers (Foda and Marmarou, 1994; Marmarou et al., 1994) has generated very important data on development of diffuse brain injuries, including an improved understanding of DAI (Povlishock et al., 1997). However, this model combines DAI with a contusion injury, which makes the model less useful for threshold studies on DAI. A number of acceleration devices have been developed for work in rodents, but the majority seems to result in more severe injuries with meningeal bleedings (Hamberger et al., 2009). A model aimed for threshold studies was described in detail at the IRCOBI conference 2009 (Davidsson et al., 2009). It is designed to produce diffuse brain injuries by rearward rotational acceleration in sagittal plane. The skull of an anesthetized adult rat is tightly secured to a rotating bar. The bar is impacted by a striker that causes the bar and the animal head to rotate rearward; the acceleration phase lasts $0.4 \mathrm{~ms}$ and is followed by a rotation at constant speed and a gentle deceleration when the bar makes contact with a padded stop (Figure 5). By adjusting the air pressure in the rifle used to accelerate the striker, rotational acceleration between 0.3 and $2.1 \mathrm{Mrad} / \mathrm{s}^{2}$ can be produced (Davidsson and Risling, 2011). The signature injury with this model is DAI in the corpus callosum, subcortical white matter, and the brain stem. The absence of cell death and excessive bleedings indicate that this is a mild TBI and effects on behavior are indeed limited. Thus, this model can add knowledge about mechanisms and thresholds for acceleration induced mild TBI and such data can be relevant for the understanding of consequences of tertiary blast. One other model of interest for acceleration induced DAI is a model described by Cernak et al. (2004), which results in a moderate TBI with edema, cell death, and an increased permeability at the Blood-Brain Barrier.

\section{MODELS FOR QUATERNARY BLAST}

Few studies are available on biological effects of EMP or heat from detonations. One example of a facility with a capacity to generate synthetic explosion-like EMP is a system at FMV (Swedish Defence Materiel Administration) in Sweden, which is mainly used to test the resistance of technical equipment to EMP. Marx generators coupled to a 90-m long antenna can generate a wide band $(\mathrm{MHz}-$ $\mathrm{GHz}$ ) pulse with field strength of up to $450 \mathrm{kV} / \mathrm{m}$. The system has recently been used for cell culture experiments. However, the importance of EMP in BINT has not been proven and exposure data from IED detonations are not available. One recent hypothesis, though, is that bone piezoelectricity (a phenomenon in which bone polarizes electrically in response to an applied mechanical stress and produces a short-range electric field) could be a source of intense blast-induced electric fields in the brain (Lee et al., 2011). Heat effects can be studied under strict laboratory conditions in cell cultures and rodents. However, the heat emission during an explosion has a short duration and it seems unlikely that heat would be an important mechanism in mild BINT cases.

\section{MISCELLANEOUS MODELS}

This includes a number of models that primarily were not designed for blast research, but may have a potential to generate data of

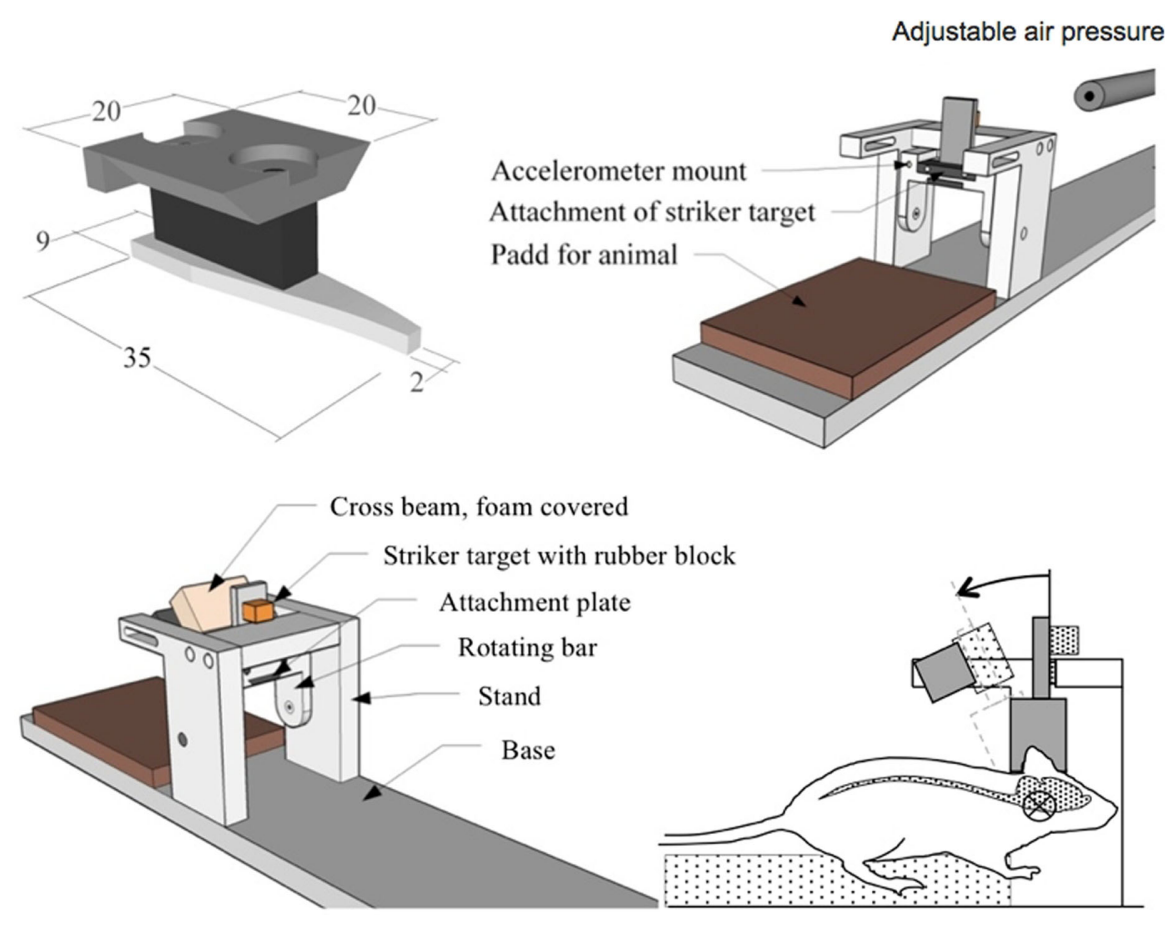

FIGURE 5 | Drawings showing a device for controlled sagittal acceleration of the rat head. A metallic plate is glued on the skull bone and is used to attach a lever that is hit by a projectile from a modified air gun. The resulting rotational acceleration has been show to induce multiple axonal injuries, resembling the clinical picture of DAI. Such rotational acceleration movements may be a component of blast injuries. 
relevance for BINT. One such example is a cell culture system in which a laser beam is used to accelerate a metal fragment to the bottom of a cell culture vial. The impact generates a shockwave with hydrodynamic cavitation in the cell culture medium (Sonden et al., 2000). Such systems can be used to examine isolated cellular mechanisms in various cell types. Other examples are cortical impact models and fluid percussion equipment that can generate generic data on mechanisms in TBI, but are difficult to translate into the more specific context of blast physics. Also a few new models designed for blast research but with limited validation should be mentioned, such as the Cranium Only Blast Injury Apparatus (Kuehn et al., 2011) and the composite blast exposure model that has been used for biomarker studies at Banyan Biomarkers (Svetlov et al., 2010).

\section{ANIMAL SPECIES AND STRAINS}

The choice of the animal species or strain can obviously have a significant impact on the outcome of the injury. Differences in body size and the geometry of the skull can be assumed to represent critical factors in experimental design. For example experiments with rotational acceleration are very dependent on the distance to the axis of rotation, thus a larger brain may be far less resistant to rotational injury. Different rat strains may exhibit different inflammatory responses and reactions to TBI (Bellander et al., 2010). Thus, the selection of strain can have a significant impact on the result. Transgenic mice and knockout models can be used to identify the impact of individual genes and may add important information to mechanisms in BINT (Koliatsos et al., 2011).

\section{NOTES ON EXPERIMENTAL DESIGN}

The seminal studies of Cernak (2010) have shown that BINT is a systemic reaction to blast. General inflammatory reactions from the primary blast can contribute to the reactions of the brain. The propagation of pressure waves through the body in blast trauma is still a subject of controversy. Important data can be retrieved by carefully designed experiments employing partial body protection (Cernak, 2010). The importance of recurrent mild TBI for development of late injuries has been documented in sports medicine (Guskiewicz et al., 2005) and repeated injuries will probably be included in a number of protocols for research on BINT. Refined behavioral tests with a high sensitivity for stress reactions similar to posttraumatic stress will be important in the future work with BINT (Kamnaksh et al., 2011; Kovesdi et al., 2011; Kwon et al., 2011).

\section{VALIDATION AND TRANSLATION}

Based on the review above, the need for additional blast injury models may be questioned. One fundamental question is how to compare existing models. For example, it would be beneficial if all blast and shock tubes could be described in the same way, with solid documentation of peak pressure, duration, rise time, positive, and negative phases, etc. It would furthermore be of help if sensors were calibrated in the same way. Implanted probes in the brain, vessels, and torso may add crucial information. Unfortunately, physics is complicated and additional research is needed to achieve relevant results without artifacts (Moore et al., 2009; MediavillaVaras et al., 2011).
Another fundamental question is how to validate existing models. Initially, an improved method of translation between animal experiments and the clinic would be to employ the same methodology for analysis. Imaging with MRI and systematic use of biomarkers can be used in both settings and help to bridge the gap between the lab bench and the hospital bed. Secondly, there is an additional need for comparison between exposure data from actual clinical situations and the test conditions employed in the animal experiments. Clinical data could for example be generated from acceleration probes in helmets, in order to measure head accelerations during blast. Due to differences in properties between humans and the animals used in the experiments, scaling of the data for differences in size, geometry, material properties, skull-to-brain tissue interface, etc., should be further introduced. Scaling techniques have been introduced and used in the past to scale injury threshold data from animals to humans. Already some 50 years ago rotational acceleration data was scaled from animals to humans using a method developed by Holbourn (1943). Unfortunately, these equations and more recent scaling techniques (Thibault and Margulies, 1998) mainly take brain inertia into account.

Advanced finite element models of the experimental conditions allow for an improved understanding of the injury mechanism and help to determine injury thresholds at tissue level. Examples of such attempts, for which rats have been used as a model of the human, are studies that focused on controlled cortical impact (Ueno et al., 1995; Shreiber et al., 1997; Pena et al., 2005; Levchakov et al., 2006; Mao et al., 2006, 2010, 2011; Pleasant et al., 2011), indentation of the head to study skull and brain injuries (Gefen et al., 2003), and rotational head trauma (Baumgartner et al., 2009; Fijalkowski et al., 2009). The suggested tissue injury thresholds could thereafter, in order to take into account differences in material properties, etc., be scaled to be valid for humans. Finally, the scaled results could be employed in detailed finite element models of the human skull and brain and used in studies that bridge experimental and clinical data.

It seems possible that future work with computer models for TBI will include more detailed information on cell density, fiber directionality, and vascular supply. Modeling of vascular supply can be used to predict blood pressure and regional flow (Lorthois et al., 2011). Exact knowledge of the blood vessel geometry should play an important role in the understanding of mechanisms for TBI (Lehmpfuhl et al., 2011). Water and solute transport across the Blood-Brain Barrier can also be assessed with mathematical modeling that might be incorporated in more detailed computer models for TBI research (Li et al., 2010). Adjustments in vascular tone or caliber of the cerebral vessels may be critical if pressure waves are propagated through blood vessels in BINT. It may therefore be relevant to model cerebral autoregulation and other homeostatic mechanisms that initiate blood flow changes in order to meet local metabolic changes after trauma (Aoi et al., 2009). Mathematical models with numerical data for vessel compliance and blood viscosity may be useful for analysis of blood in complex, multi-branching vascular networks, and thereby enable predictions of circulation in critical areas such as the hippocampus. One example of such work, is the virtual fractal model of the vasculature in the middle cerebral artery region (Bui et al., 2009). 
Visco-elastic properties of blood vessels have been represented in the visco-elastic Windkessel model (Zheng and Mayhew, 2009). At a molecular level the dynamics of oxygen transport in the brain are crucial to its response to local mismatches between flow and metabolism. A two phase continuum model, based on the coupled behavior of oxygen transport in tissue and blood, that can be use to simulate micro-strokes, has been described (Su and Payne, 2009). Models of biological neural networks are used to find out how synchronized firing of neurons arise and may therefore provide understanding of focal epilepsy after TBI (Volk, 2001; David et al., 2009). One further development might be to combine such models with artificial neural networks as tools that can be applied as predictive models (Rughani et al., 2010; van der Ploeg et al., 2011).

The most central problem, however, is that exposure data from actual clinical situations are lacking. Acceleration probes mounted in helmets (Rigby et al., 2011) may help to solve this problem. If the same type of sensors will be implanted for use in animal

\section{REFERENCES}

Agoston, D. V., Risling, M., and Bellander, B.-M. (2012). Benchto-bedside and bedside back to the bench; coordinating clinical and experimental traumatic brain injury studies. Front. Neurol. 3:3. doi:10.3389/fneur.2012.00003

Aoi, M., Gremaud, P., Tran, H. T., Novak, V., and Olufsen, M. S. (2009). Modeling cerebral blood flow and regulation. Conf. Proc. IEEE Eng. Med. Biol. Soc. 2009, 5470-5473.

Armonda, R. A., Bell, R. S., Vo, A. H., Ling, G., DeGraba, T. J., Crandall, B., Ecklund, J., and Campbell, W. W. (2006). Wartime traumatic cerebral vasospasm: recent review of combat casualties. Neurosurgery 59, 1215-1225; discussion 1225.

Axelsson, H., and Yelverton, J. T. (1996). Chest wall velocity as a predictor of nonauditory blast injury in a complex wave environment. J. Trauma. 40, S31-S37.

Bauman, R. A., Ling, G., Tong, L., Januszkiewicz, A., Agoston, D., Delanerolle, N., Kim, Y., Ritzel, D., Bell, R., Ecklund, J., Armonda, R., Bandak, F., and Parks, S. (2009). An introductory characterization of a combat-casualty-care relevant swine model of closed head injury resulting from exposure to explosive blast. J. Neurotrauma 26, $841-860$.

Baumgartner, D., Lamy, M., Willinger, R., Choquet, P., Goetz, C., Costantinesco, A., and Davidsson, J. (2009). "Finite element analysis of traumatic brain injuries mechanisms in the rat," in Proceedings of the 2009 IRCOBI Conference, York.

Belanger, H. G., Proctor-Weber, Z., Kretzmer, T., Kim, M., French, L. M., and
Vanderploeg, R. D. (2011). Symptom complaints following reports of blast versus non-blast mild TBI: does mechanism of injury matter? Clin. Neuropsychol. 25, 702-715.

Bellander, B. M., Lidman, O., Ohlsson, M., Meijer, B., Piehl, F., and Svensson, M. (2010). Genetic regulation of microglia activation, complement expression, and neurodegeneration in a rat model of traumatic brain injury. Exp. Brain Res. 205, 103-114.

Bui, A., Sutalo, I. D., Manasseh, R., and Liffman, K. (2009). Dynamics of pulsatile flow in fractal models of vascular branching networks. Med. Biol. Eng. Comput. 47, 763-772.

Celander, H., Clemedson, C. J., Ericsson, U. A., and Hultman, H. I. (1955). The use of a compressed air operated shock tube for physiological blast research. Acta Physiol. Scand. 33, 6-13.

Cernak, I. (2005). Animal models of head trauma. NeuroRx 2, 410-422.

Cernak, I. (2010). The importance of systemic response in the pathobiology of blast-induced neurotrauma. Front. Neurol. 1:151. doi:10.3389/fneur.2010.00151

Cernak, I., Merkle, A. C., Koliatsos, V. T. M., Xu, L., Slack, N., Windle, D., and Ahmed, F. A. (2011). The pathobiology of blast injuries and blastinduced neurotrauma as identified using a new experimental model of injury in mice. Neurobiol. Dis. 41, 538-551.

Cernak, I., and Noble-Haeusslein, L. J. (2010). Traumatic brain injury: an overview of pathobiology with emphasis on military populations. J. Cereb. Blood Flow Metab. 30, 255-266. E., Bilik, J. M., Luong, Q. T., Mahota,

experiments, translation of data may be facilitated. One other way to accomplish a better translation between animal experiments and the clinic would be to employ the same methodology for analysis (Agoston et al., 2012). Imaging with MRI and systematic use of biomarkers can be used in both settings and help to decrease the gap between the lab bench and the hospital bed. Computer based reconstruction of clinical injuries and exposure in the experimental models can help to further improve knowledge of this area (Kleiven, 2007). Modeling however, has limited use if the predictions cannot be validated by actual biological observations. Outcome data from a large cohort of patients that survived penetrating brain injuries is available through the Vietnam Head injury study (Raymont et al., 2011; Rostami et al., 2011). This is probably the most detailed follow-up neurotrauma study that has ever been conducted and it could serve as model for how useful data should be collected. Hopefully, similar data collections will be available for BINT and can help to indicate suitable designs for relevant experimental studies.

Cernak, I., Vink, R., Zapple, D. N., Cruz, M. I., Ahmed, F., Chang, T., Fricke, S. T., and Faden, A. I. (2004). The pathobiology of moderate diffuse traumatic brain injury as identified using a new experimental model of injury in rats. Neurobiol. Dis. 17, 29-43.

Chavko, M., Koller, W. A., Prusaczyk, W. K., and McCarron, R. M. (2007). Measurement of blast wave by a miniature fiber optic pressure transducer in the rat brain. J. Neurosci. Methods 159, 277-281.

Chavko, M., Watanabe, T., Adeeb, S. Lankasky, J., Ahlers, S. T., and McCarron, R. M. (2011). Relationship between orientation to a blast and pressure wave propagation inside the rat brain. J. Neurosci. Methods 195, 61-66.

Chen, Y., and Huang, W. (2011). Nonimpact, blast-induced mild TBI and PTSD: concepts and caveats. Brain Inj. 25, 641-650.

Clemedson, C. J. (1956). Shock wave transmission to the central nervous system. Acta Physiol. Scand. 37, 204-214.

Clemedson, C. J., and Criborn, C. O. (1955). A detonation chamber for physiological blast research. J. Aviat. Med. 26, 373-381.

Clemedson, C. J., Hartelius, H., and Holmberg, G. (1957). The effect of high explosive blast on the cerebral vascular permeability. Acta Pathol. Microbiol. Scand. 40, 89-95.

Clemedson, C. J., Hultman, H., and Gronberg, B. (1953). Respiration and pulmonary gas exchange in blast injury. J. Appl. Physiol. 6, 213-220.

Clemedson, C. J., and Hultman, H. I. (1954). Air embolism and the cause of death in blast injury. Mil. Surg. 114, 424-437.

David, Y., Cacheaux, L. P., Ivens, S., Lapilover, E., Heinemann, U., Kaufer, D., and Friedman, A. (2009). Astrocytic dysfunction in epileptogenesis: consequence of altered potassium and glutamate homeostasis? J. Neurosci. 29, 10588-10599.

Davidsson, J., Angeria, M., and Risling, M. (2009). "Injury threshold for sagittal plane rotational induced diffuse axonal injuries," in International IRCOBI Conference on the Biomechanics of Injury, ed. K. U. Schmitt (York), 43-56.

Davidsson, J., and Risling, M. (2011). A new model to produce sagittal plane rotational induced diffuse axonal injuries. Front. Neurol. 2:41. doi:10.3389/fneur.2011.00041

de Lanerolle, N. C., Bandak, F., Kang, D., Li, A. Y., Du, F., Swauger, P., Parks, S., Ling, G., and Kim, J. H. (2011). Characteristics of an explosive blastinduced brain injury in an experimental model. J. Neuropathol. Exp. Neurol. 70, 1046-1057.

Fijalkowski, R. J., Yoganandan, N., Zhang, J., and Pintar, F. A. (2009). A finite element model of regionspecific response for mild diffuse brain injury. Stapp Car Crash J. 53, 193-213.

Foda, M. A., and Marmarou, A. (1994). A new model of diffuse brain injury in rats. Part II: morphological characterization. J. Neurosurg. 80, 301-313.

Gefen, A., Gefen, N., Zhu, Q., Raghupathi, R., and Margulies, S. S. (2003) Age-dependent changes in material properties of the brain and braincase of the rat. J. Neurotrauma 20, 1163-1177. 
Guskiewicz, K. M., Marshall, S. W., Bailes, J., McCrea, M., Cantu, R. C., Randolph, C., and Jordan, B. D. (2005). Association between recurrent concussion and late-life cognitive impairment in retired professional football players. Neurosurgery 57, 719-726.

Hamberger, A., Viano, D. C., Saljo, A., and Bolouri, H. (2009). Concussion in professional football: morphology of brain injuries in the NFL concussion model - part 16. Neurosurgery 64, 1174-1182; discussion 1182.

Hoge, C. W., Goldberg, H. M., and Castro, C. A. (2009). Care of war veterans with mild traumatic brain injury-flawed perspectives. N. Engl. J. Med. 360, 1588-1591.

Holbourn, A. H. (1943). Mechanics of head injuries. Lancet 2, 438-441.

Jaffee, M. S., Helmick, K. M., Girard, P. D., Meyer, K. S., Dinegar, K., and George, K. (2009). Acute clinical care and care coordination for traumatic brain injury within Department of Defense. J. Rehabil. Res. Dev. 46, 655-666.

Kamnaksh, A., Kovesdi, E., Kwon, S. K., Wingo, D., Ahmed, F., Grunberg, N. E., Long, J., and Agoston, D. V. (2011). Factors affecting blast traumatic brain injury. J. Neurotrauma 28, 2145-2153.

Kleiven, S. (2007). Predictors for traumatic brain injuries evaluated through accident reconstructions. Stapp Car Crash J. 51, 81-114.

Koliatsos, V. E., Cernak, I., Xu, L., Song, Y., Savonenko, A., Crain, B. J., Eberhart, C. G., Frangakis, C. E., Melnikova, T., Kim, H., and Lee, D. (2011). A mouse model of blast injury to brain: initial pathological, neuropathological, and behavioral characterization. J. Neuropathol. Exp. Neurol. 70, 399-416.

Kovesdi, E., Gyorgy, A. B., Kwon, S. K., Wingo, D. L., Kamnaksh, A., Long, J. B., Kasper, C. E., and Agoston, D. V. (2011). The effect of enriched environment on the outcome of traumatic brain injury; a behavioral, proteomics, and histological study. Front. Neurosci. 5:42. doi:10.3389/fnins.2011.00042

Kuehn, R., Simard, P. F., Driscoll, I., Keledjian, K., Ivanova, S., Tosun, C., Williams, A., Bochicchio, G., Gerzanich, V., and Simard, J. M. (2011). Rodent model of direct cranial blast injury. J. Neurotrauma 28, 2155-2169.

Kwon, S. K., Kovesdi, E., Gyorgy, A. B., Wingo, D., Kamnaksh, A., Walker, J., Long, J. B., and Agoston, D. V. (2011). Stress and traumatic brain injury: a behavioral, proteomics, and histological study. Front. Neurol. 2:12. doi:10.3389/fneur.2011.00012

Lee, K. Y., Nyein, M. K., Moore, D. F., Joannopoulos, J. D., Socrate, S., Imholt, T., Radovitzky, R., and Johnson, S. G. (2011). Blast-induced electromagnetic fields in the brain from bone piezoelectricity. Neuroimage 54(Suppl. 1), S30-S36.

Lehmpfuhl, M. C., Hess, A., Gaudnek, M. A., and Sibila, M. (2011). Fluid dynamic simulation of rat brain vessels, geometrically reconstructed from MR-angiography and validated using phase contrast angiography. Phys. Med. 27, 169-176.

Levchakov, A., Linder-Ganz, E., Raghupathi, R., Margulies, S. S., and Gefen, A. (2006). Computational studies of strain exposures in neonate and mature rat brains during closed head impact. J. Neurotrauma 23, 1570-1580.

Li, G., Yuan, W., and Fu, B. M. (2010). A model for the blood-brain barrier permeability to water and small solutes. J. Biomech. 43, 2133-2140.

Ling, G. S., and Ecklund, J. M. (2011). Traumatic brain injury in modern war. Curr. Opin. Anaesthesiol. 24, 124-130.

Long, J. B., Bentley, T. L., Wessner, K. A., Cerone, C., Sweeney, S., and Bauman, R. A. (2009). Blast overpressure in rats: recreating a battlefield injury in the laboratory. J. Neurotrauma 26, 827-840.

Lorthois, S., Cassot, F., and Lauwers, F. (2011). Simulation study of brain blood flow regulation by intracortical arterioles in an anatomically accurate large human vascular network: part I: methodology and baseline flow. Neuroimage 54, 1031-1042.

Lu, J., Ng, K. C., Ling, G., Wu, J., Poon, D. J., Kan, E. M., Tan, M. H., Wu, Y. J., Li, P., Moochhala, S., Yap, E., Lee, L. K., Teo, M., Yeh, I. B., Sergio, D. M., Chua, F., Kumar, S. D., and Ling, E. A. (2011). Effect of blast exposure on the brain structure and cognition in Macaca fascicularis. J. Neurotrauma. PMID: 21639720. [Epub ahead of print].

Mao, H., Guan, F., Han, X., and Yang, K. H. (2011). Strain-based regional traumatic brain injury intensity in controlled cortical impact: a systematic numerical analysis. J. Neurotrauma 28, 2263-2276.

Mao, H., Jin, X., Zhang, L., Yang, K. H., Igarashi, T., Noble-Haeusslein, L. J., and King, A. I. (2010). Finite element analysis of controlled cortical impact-induced cell loss. J. Neurotrauma 27, 877-888.
Mao, H., Zhang, L., Yang, K. H., and King, A. I. (2006). Application of a finite element model of the brain to study traumatic brain injury mechanisms in the rat. Stapp Car Crash J. 50, 583-600.

Marmarou, A., Foda, M. A., van den Brink, W., Campbell, J., Kita, H., and Demetriadou, K. (1994). A new model of diffuse brain injury in rats. Part I: pathophysiology and biomechanics. J. Neurosurg. 80, 291-300.

MediavillaVaras, J., Philippens, M., Meijer, S. R., van den Berg, A. C., Sibma, P. C., van Bree, J. L., and de Vries, D. V. (2011). Physics of IED blast shock tube simulations for mTBI research. Front. Neurol. 2:58. doi:10.3389/fneur.2011.00058

Moore, D. F., and Jaffee, M. S. (2010). Military traumatic brain injury and blast. NeuroRehabilitation 26 179-181.

Moore, D. F., Jerusalem, A., Nyein, M., Noels, L., Jaffee, M. S., and Radovitzky, R. A. (2009). Computational biology - modeling of primary blast effects on the central nervous system. Neuroimage 47(Suppl. 2), T10-T20.

Pena, A., Pickard, J. D., Stiller, D., Harris, N. G., and Schuhmann, M. U. (2005). Brain tissue biomechanics in cortical contusion injury: a finite element analysis. Acta Neurochir. Suppl. 95, 333-336.

Plantman, S., Ng, K. C., Lu, J., Davidsson, J., and Risling, $\mathrm{M}$. (2011). Characterization of a novel rat model of penetrating traumatic brain injury. J. Neurotrauma. doi:10.1089/neu.2011.2182. [Epub ahead of print]

Pleasant, J. M., Carlson, S. W., Mao, H., Scheff, S. W., Yang, K. H., and Saatman, K. E. (2011). Rate of neurodegeneration in the mouse controlled cortical impact model is influenced by impactor tip shape: implications for mechanistic and therapeutic studies. J. Neurotrauma 28, 2245-2262.

Povlishock, J. T., Marmarou, A., McIntosh, T., Trojanowski, J. Q., and Moroi, J. (1997). Impact acceleration injury in the rat: evidence for focal axolemmal change and related neurofilament sidearm alteration. J. Neuropathol. Exp. Neurol. 56, 347-359.

Raymont, V., Salazar, A. M., Krueger, F. and Grafman, J. (2011). "Studying injured minds" - the Vietnam head injury study and 40 years of brain injury research. Front. Neurol. 2:15. doi:10.3389/fneur.2011.00015

Richmond, D. R., Damon, E. G., Bowen, I. G., Fletcher, E. R., and White, C. S. (1967a). Air-blast studies with eight species of mammals. Techn Progr Rep DASA 1854. Fission Prod. Inhal. Proj. 1-44.

Richmond, D. R., Damon, E. G., Fletcher, E. R., Bowen, I. G., and White, C. S. (1967b). The relationship between selected blast-wave parameters and the response of mammals exposed to air blast. Techn Progr Rep DASA 1860. Fission Prod. Inhal. Proj. 1-36.

Rigby, P., Wong, J., Juhas, B., Eslami, P., Rapo, M., and Baumer, T. (2011). "Using helmet sensors in predicting head kinematics," in A Survey of Blast Injury across the Full Landscape of Military Science - NATO HFM-207, Halifax.

Risling, M., Plantman, S., Angeria, M., Rostami, E., Bellander, B. M., Kirkegaard, M., Arborelius, U., and Davidsson, J. (2011). Mechanisms of blast induced brain injuries, experimental studies in rats. Neuroimage 54(Suppl. 1), S89-S97.

Risling, M., Sköld, M., Larsson, I. L., Angeria, M., and Davidsson, J. (2004). "Leakage of S-100 protein after high velocity penetration injury to the brain," in 7th International Neurotrauma Symposium (Adelaide: Medimond), 119-124.

Rostami, E., Krueger, F., Zoubak, S., Dal Monte, O., Raymont, V., Pardini, M., Hodgkinson, C. A., Goldman, D., Risling, M., and Grafman, J. (2011). BDNF polymorphism predicts general intelligence after penetrating traumatic brain injury. PLoS ONE 6, e27389. doi:10.1371/journal.pone.0027389

Rubovitch, V., Ten-Bosch, M., Zohar, O., Harrison, C. R., Tempel-Brami, C., Stein, E., Hoffer, B. J., Balaban, C. D., Schreiber, S., Chiu, W. T., and Pick, C. G. (2011). A mouse model of blast-induced mild traumatic brain injury. Exp. Neurol. 232, 280-289.

Rughani, A. I., Dumont, T. M., Lu, Z., Bongard, J., Horgan, M. A., Penar, P. L., and Tranmer, B. I. (2010). Use of an artificial neural network to predict head injury outcome. $J$. Neurosurg. 113, 585-590.

Sayer, N. A. (2012). Traumatic brain injury and its neuropsychiatric sequelae in war veterans (*). Annu. Rev. Med. 63, 405-419.

Sharp, D. J., and Ham, T. E. (2011). Investigating white matter injury after mild traumatic brain injury. Curr. Opin. Neurol. 24, 558-563.

Shreiber, D. I., Bain, A. C., and Meaney, D. F. (1997). "In vivo thresholds for mechanical injury to the blood-brain barrier," in 41st Stapp 
Car Crash Conference, Lake Buena Vista.

Snell, F. I., and Halter, M. J. (2010). A signature wound of war: mild traumatic brain injury. J. Psychosoc. Nurs. Ment. Health Serv. 48, 22-28.

Sonden, A., Svensson, B., Roman, N., Ostmark, H., Brismar, B., Palmblad, J., and Kjellstrom, B. T. (2000). Laser-induced shock wave endothelial cell injury. Lasers Surg. Med. 26, 364-375.

Su, S. W., and Payne, S. J. (2009). A two phase model of oxygen transport in cerebral tissue. Conf. Proc. IEEE Eng. Med. Biol. Soc. 2009, 4921-4924.

Svetlov, S. I., Prima, V., Kirk, D. R., Gutierrez, H., Curley, K. C., Hayes, R. L., and Wang, K. K. (2010). Morphologic and biochemical characterization of brain injury in a model of controlled blast overpressure exposure. J. Trauma. 69, 795-804.

Terrio, H., Brenner, L. A., Ivins, B. J., Cho, J. M., Helmick, K., Schwab, K., Scally, K., Bretthauer, R., and Warden, D. (2009). Traumatic brain injury screening: preliminary findings in a US Army Brigade Combat Team. J. Head Trauma Rehabil. 24, 14-23.

Thibault, K. L., and Margulies, S. S. (1998). Age-dependent material properties of the porcine cerebrum: effect on pediatric inertial head injury criteria. J. Biomech. 31, 1119-1126.

Ueno, K., Melvin, J. W., Li, L., and Lighthall, J. W. (1995). Development of tissue level brain injury criteria by finite element analysis. J. Neurotrauma 12, 695-706.

van der Ploeg, T., Smits, M., Dippel, D. W., Hunink, M., and Steyerberg, E. W. (2011). Prediction of intracranial findings on CTscans by alternative modelling techniques. BMC Med. Res. Methodol. 11, 143. doi:10.1186/1471-228811-143

Volk, D. (2001). Population oscillations in a discrete model of neural net- works of the brain. BioSystems 63 35-41.

White, C. S., Bowen, I. G., and Richmond, D. R. (1965). Biological tolerance to air blast and related biomedical criteria. CEX65.4. CEX Rep. Civ. Eff. Exerc. 1-239.

Williams, A. J., Hartings, J. A., Lu, X. C. Rolli, M. L., Dave, J. R., and Tortella, F. C. (2005). Characterization of a new rat model of penetrating ballistic brain injury. J. Neurotrauma 22, 313-331.

Williams, A. J., Wei, H. H., Dave, J. R., and Tortella, F. C. (2007). Acute and delayed neuroinflammatory response following experimental penetrating ballistic brain injury in the rat. J. Neuroinflammation 4 17.

Zheng, Y., and Mayhew, J. (2009). A time-invariant visco-elastic Windkessel model relating blood flow and blood volume. Neuroimage 47, 1371-1380.
Conflict of Interest Statement: The authors declare that the research was conducted in the absence of any commercial or financial relationships that could be construed as a potential conflict of interest.

Received: 30 October 2011; accepted: 16 February 2012; published online: 02 April 2012.

Citation: Risling $M$ and Davidsson J (2012) Experimental animal models for studies on the mechanisms of blastinduced neurotrauma. Front. Neur. 3:30. doi: 10.3389/fneur.2012.00030

This article was submitted to Frontiers in Neurotrauma, a specialty of Frontiers in Neurology.

Copyright $(\odot 2012$ Risling and Davidsson. This is an open-access article distributed under the terms of the Creative Commons Attribution Non Commercial License, which permits non-commercial use, distribution, and reproduction in other forums, provided the original authors and source are credited. 